\title{
A REFLEXÃO E INVESTIGAÇÃO DA PRÓPRIA PRÁTICA NA FORMAÇÃO INICIAL E CONTINUADA: contribuição das dissertações e teses no período 1997-2002
}

\author{
The reflection and investigation of practice itself inside \\ initial and continuous development: dissertations and \\ theses contributions from 1997 through 2002
}

\section{Elsa Garrido ${ }^{\text {a }}$ Iria Brzezinski ${ }^{\mathrm{b}}$}

a Professora livre-docente da Faculdade de Educação da USP. Universidade de São Paulo, São Paulo - Brasil, e-mail: egarrido@usp.br

b Professora no Programa de Pós-Graduação em Educação da Universidade Católica de Goiás (UCG) - Goiânia, Goiás - Brasil, e-mail: iria@ucg.br

\section{Resumo}

Este estudo mapeia e traz as contribuições da pesquisa sobre a Formação do Professor Reflexivo/investigativo encontrada nas dissertações e teses defendidas em 23 programas de pós-graduação em Educação do Brasil, no período 1997-2002. Constitui recorte de levantamento mais amplo sobre o Estado do Conhecimento da Formação de Profissionais da Educação, em que foram analisados 792 títulos. Desse universo levantamos 169 trabalhos, dos quais 14 abordaram aspectos conceituais e teóricos da epistemologia da prática; 20 analisaram experiências nas quais os formadores de professores transformaram seu ensino em objeto de pesquisa, ao mesmo tempo em que os licenciandos foram introduzidos em 
atividades de reflexão e de investigação; e 135 relataram experiências de formação continuada, fruto de parcerias entre pesquisadores e professores da educação básica ou de movimentos de autoformação.

Palavras-chave: Formação do professor reflexivo/investigativo; Formação de professores Formação inicial; Formação continuada; Professor-pesquisador.

\begin{abstract}
This study deals and brings some research contributions on the Reflective/Inquirer Teacher Development, which have found and justified inside dissertations and theses of 23 programs in Education in Brazil from 1997 through 2002. It represents an extensive survey clipping around the State of Knowledge in Professional Development of Education, where has been analyzed around 792 titles. From all those titles, 169 were raised; and 14 have brought concepts and theoretical aspects on practice epistemology; 20 have analyzed some experiences in which teachers' formative have changed their own teaching into an investigation goal, at the same time licentiate were introduced into investigation and reflective activities; 135 have enrolled continuous development experiences which had resulted from a partnership between teachers and researchers of basic education or self-formation groups.
\end{abstract}

Keywords: Reflective/inquirer development teacher; Initial development in teachers' development; Continuous development; Inquirer teacher.

\title{
INTRODUÇÃO
}

O presente estudo traz a contribuição de uma amostra representativa das dissertações e teses defendidas nos Programas de Pós-graduação de Educação no período 1997-2002 sobre a formação do professor reflexivo/investigativo. ${ }^{1}$

1 Esta pesquisa faz parte de um projeto mais amplo denominado Formação de profissionais da educação (1997-2002), coordenado por Iria Brzezinski (2006), que dá continuidade à Formação dos professores no Brasil (1990-1998), coordenado por Marli André (2002).

Rev. Diálogo Educ., Curitiba, v. 8, n. 23, p. 153-171, jan./abr. 2008 
A reflexão e investigação da própria prática na formação inicial e continuada

A concepção de que a análise sistemática que o professor empreende sobre sua prática contribui para a qualidade do ensino e da aprendizagem tornouse um movimento vigoroso no mundo, a partir dos anos 90, destacando-se a produção de alguns centros liderados, entre outros, por Schon, Shulman, Zeichner, Cochran-Smith, Lytle, Fullan, Popkewitz, Giroux, nos Estados Unidos; Stenhouse e Elliott, na Inglaterra; Carr, Kemmis, Baird, na Austrália; Gimeno Sacristán, Gil Perez, Contreras, na Espanha; Alarcão e Nóvoa, em Portugal.

Ser professor investigativo significa buscar esclarecer os problemas que ele e seus colegas vivenciam no cotidiano escolar, problemas de início confusos e polêmicos, porque envolvem pessoas, valores, crenças, interesses, freqüentemente em conflito; significa aprofundar a compreensão dessas questões, procurando ouvir e respeitar os diferentes atores (professores, alunos, pais), para propor alternativas aceitáveis pelo grupo, a serem experienciadas, analisadas e aperfeiçoadas, tornando o ensino pesquisa, pesquisa na ação. Nesse contexto, o papel do professor ganha expressão e a escola passa a ser um espaço privilegiado de formação profissional.

A "reflexão na ação" faz o profissional tomar consciência de sua forma intuitiva e tácita de atuar. Introduz o pensar no fazer. Torna sua ação lúcida, não rotineira, atenta e sensível - como bem expressa uma professora participante de um grupo de pesquisa colaborativa centrada na escola:

Passei a sentir-me sujeito de minha prática, pois passei a colocar como objeto de estudo a minha própria ação como professora. Vejo que a prática cotidiana do professor é um desafio permanente, que resiste a fórmulas ou soluções prontas. Na realidade é um convite para um ensino criativo, experimental e que permite pesquisa na ação. (GARRIDO, 2000, p. 10).

A "pesquisa na prática" ou "reflexão sobre a reflexão na ação" em que os professores envolvidos ressignificam suas práticas e propõem novas estratégias de ação, torna o próprio processo de intervenção objeto de pesquisa. A natureza processual marca a investigação reflexiva. O professor-pesquisador, ao intervir, muda a realidade que estuda. E ele próprio também se modifica: passa a ter outra compreensão da situação. Por sua vez, os outros agentes também mudam a realidade, como resposta às inovações introduzidas. Cria-se uma espiral de mudança que precisa ser investigada, para poder ser aperfeiçoada.

A credibilidade da reflexão e da investigação do professor foi desde o início posta em questão: o termo reflexão é genérico e ambíguo, podendo designar desde uma opinião apressada até o ensaio de um filósofo; a urgência nas tomadas de decisão e o fato do próprio sujeito envolvido investigar seu

Rev. Diálogo Educ., Curitiba, v. 8, n. 23, p. 153-171, jan./abr. 2008 
trabalho introduzem alto grau de subjetividade e viés às análises. Daí a importância do caráter intersubjetivo do processo reflexivo e da socialização dos resultados, submetendo o trabalho à apreciação dos pares e do público em geral. A necessidade de tornar o trabalho educativo público obriga o professor a explicitar e fundamentar suas opções, a sistematizar a reflexão e a (d)escrever seu fazer. Tudo isso contribui para o desenvolvimento profissional e para a qualificação do ensino. O professor torna-se mais metódico: registra, documenta. Sua observação e interpretação se aguçam.

Reconhecer os constrangimentos sociológicos, históricos e ideológicos das práticas pedagógicas e da cultura escolar dá à reflexão dimensão "crítica", dá à intervenção caráter emancipatório, tornando o professor agente de transformação social.

Qual o valor epistemológico da pesquisa do professor? Borko (2004) e Putnam, Costa e Garrido (2002) denominam-no "conhecimento situacional" e Cochran-Smith e Lytle (1999) caracterizam-no como "conhecimento prático situacional".

Noffke (1997), Crochran-Smith e Lytle (1999) Zeichner (2003) e Borko (2004) examinaram pesquisas e programas cujos projetos de formação continuada basearam-se na perspectiva do professor reflexivo/investigativo. Procuraram pôr em evidência os contextos em que ocorreram, as condições que favoreceram o desenvolvimento profissional dos docentes envolvidos, as mudanças que trouxeram na cultura escolar e as características que marcaram esse tipo de formação.

Todos esses estudos reconheceram a relevância da pesquisa do professor na formação, no desenvolvimento profissional e na mudança da cultura escolar. Ela tem efeitos profundos sobre os professores participantes: tornaramnos mais autônomos, mais criativos, mais abertos a mudanças, mais capazes de analisar seu ensino e a aprendizagem dos alunos, mais comprometidos com a profissão e entusiasmados com o ato de ensinar.

Foram fatores importantes no processo de desenvolvimento profissional docente: a) a partilha, o trabalho em grupo, os projetos conjuntos; b) o registro e documentação da prática pedagógica (vídeos de aulas, produções dos alunos, diários de campo; c) o papel do pesquisador (de respeito aos professores, de suporte, de orientação e de instigador intelectual); d) as rotinas e normas de interação e de compromisso com o grupo; e) a socialização da experiência: rede entre professores, publicação, apresentação em congressos.

Criar uma cultura de investigação que respeita o professor não se impõe de cima para baixo. É preciso reconhecer seus saberes e suas prioridades investigativas, centrando as pesquisas nas questões e nos temas dos professores.

Rev. Diálogo Educ., Curitiba, v. 8, n. 23, p. 153-171, jan./abr. 2008 
A reflexão e investigação da própria prática na formação inicial e continuada

Quando o programa não respeitou a temática do professor, orientando a pesquisa segundo as prioridades colocadas pelo sistema de ensino, observou-se tensão no grupo. Respeitar os saberes dos professores não significa aceitar acriticamente sua colaboração. Cabe ao pesquisador colaborador a arte de desafiar intelectualmente os participantes, desencadeando desequilíbrios produtivos. Cabe também orientá-los nos caminhos da pesquisa, atividade nova para os professores. Criar rotinas de estudo, de organização das atividades do grupo. E ainda dar-lhes suporte, criando condições protegidas e reforçadoras para os riscos e dificuldades da tarefa de repensar-se e de repensar a escola (ZEICHNER, 2003).

A cultura de análise não é espontânea. É complexa. É arriscada e se dá sob pressão do tempo e dos conflitos (valores, crenças, interesses, ideologias). O desenvolvimento de comunidades investigativas demanda tempo: pelo menos um ano, com reuniões periódicas. Na casuística de Borko (2004) elas ocorreram, em geral, a cada 2 ou 3 semanas. Após o primeiro ano, observouse salto de qualidade na capacidade investigativa dos professores: tornaram-se mais aguçados nas interpretações, mais sensíveis ao raciocínio dos alunos, passaram a criar estratégias instrucionais, viam suas salas de aula como espaços em que eles também aprendiam. Núcleos e instituições com grupos consolidados produziram projetos diversificados e mudanças mais significativas no ensino e aprendizagem, graças ao suporte, ao compromisso grupal e à existência de rotinas normatizadas (BORKO, 2004).

O impacto desses resultados esbarra na centralização do sistema educacional, na desvalorização da profissão e das condições de trabalho docente.

Zeichner (2003) pontuou, entretanto, algumas limitações nas pesquisas examinadas. De um lado, muitos relatos não constituem pesquisa, porque a experiência desenvolvida não foi registrada, não houve uma forma sistemática de implementação, as reuniões não tiveram uma agenda - foram vivências de partilhas, sem exploração sistemática das questões. Por outro lado, muitos relatos de pesquisa trazem pouca informação sobre as condições que favoreceram o processo de desenvolvimento profissional dos professores e sobre as rotinas das reuniões: Que normas de funcionamento foram sendo criadas e modificadas? Como se deu a organização dos pequenos grupos? Que orientações foram dadas aos professores sobre a nova natureza investigativa que seu trabalho passou a ter: o que registrar? Como registrar? Que tipos de registro? Como analisá-los? Como escrever o relatório de pesquisa? Assinala ainda que são poucas as pesquisas sobre o impacto dessa perspectiva formativa sobre os alunos e sobre a cultura escolar.

Trouxemos os resultados desses levantamentos como referências para analisar as contribuições das dissertações e teses sobre a formação do

Rev. Diálogo Educ., Curitiba, v. 8, n. 23, p. 153-171, jan./abr. 2008 
professor reflexivo/investigativo, defendidas no período 1997-2002. Ainda que restritos aos aspectos próprios da formação continuada, tais estudos ajudaram-nos a reconhecer a existência de traços comuns entre as duas realidades e de enfoques formativos próprios da nossa cultura e da nossa história de ensino e pesquisa.

Tendo em vista a potencialidade da perspectiva do professor reflexivo, procuramos neste estudo fazer um mapeamento dos enfoques abordados nas dissertações e teses sobre Formação de Professores no período 1997-2002, com o objetivo de verificar quão expressiva foi a temática da formação do professor reflexivo/ investigativo no conjunto dessa produção? Quão expressiva foi a apropriação desse movimento entre os formadores? Os formadores investigaram suas práticas docentes? Como os alunos dos cursos de Pedagogia e de Licenciatura foram introduzidos na reflexão e investigação da prática na formação inicial? E na formação continuada, como se deu o processo de aprender a pesquisar a própria prática, atividade nova para o professor da Educação Básica? Que mudanças produziram nas práticas escolares? Qual o papel do pesquisador e da universidade nesse processo?

\section{METODOLOGIA DA PESQUISA}

O levantamento e análise das dissertações e teses de doutorado, defendidas nos Programas de Pós-Graduação do Brasil credenciados pela CAPES, no período de 1997-2002, realizou-se em três etapas:

a) levantamento documental dos resumos, junto ao acervo da Anped, à homepage da Capes e ao Relatório de Avaliação de Programas de Pós-graduação Stricto Sensu da Área de Educação (2003), no qual constam os resumos da produção discente; ${ }^{2}$

b) mapeamento do universo de dissertações e teses por instituição e ano;

2 Foram selecionados todos os resumos que continham em seu texto os seguintes descritores ou palavras-chave: formação de professor, formação do educador, formação docente, formação inicial, magistério de segundo grau, escola normal, HEM, CEFAM, professor leigo, pedagogia, licenciatura, instituto de educação superior, escola normal superior, formação continuada, formação de formadores, formação a distância, estágio, prática, práticas docentes, práticas pedagógicas, sala de aula, discurso em sala de aula, relação professor-aluno, representações do professor, concepções do professor, desenvolvimento profissional docente, professor reflexivo, professor investigativo, políticas de formação, LDBEN, identidade, profissionalização, profissionalidade, saberes, competências, histórias/vida de professores, gênero, representações sobre o professor.

Rev. Diálogo Educ., Curitiba, v. 8, n. 23, p. 153-171, jan./abr. 2008 
A reflexão e investigação da própria prática na formação inicial e continuada

c) seleção de uma amostra representativa da produção ${ }^{3}$ para leitura do texto integral, diante da insuficiência de dados dos resumos, do elevado número e da dificuldade de localização da produção;

d) leitura integral da produção da amostra e elaboração de resumos expandidos sobre cada uma delas; ${ }^{4}$

e) mapeamento dos resumos expandidos.

Das 748 dissertações e teses da amostra, 6 foram eliminadas por não focalizarem o tema da formação na investigação, mencionando-o apenas nas conclusões.

\section{ANÁLISE DOS DADOS}

\section{A produção discente sobre formação de professores nos programas de pós-graduação de educação nos períodos 1990- 1996 e 1997-2002}

A Tabela 1 mostra o crescimento relativo da produção discente sobre Formação de Professores produzida nos Programas de Pós-graduação de Educação nos períodos 1990-1996 e 1997-2002, em comparação com o total dessa produção.

No período 1997-2002, o campo da investigação se alarga, quando comparado ao período anterior 1990-1996. Registramos no segundo período um total de 8.085 títulos, representando um aumento de $89 \%$ em relação à produção de 4.492 estudos, levantada no período 1990-1996, fruto do considerável aumento dos programas de Pós-graduação de Educação no Brasil, passando de 16 em 1990 para 50 em 2002.

3 Dos programas Critérios de seleção dos Programas de Pós-graduação - Os Programas a serem selecionados deveriam: 1) espelhar a diversidade institucional, constituída por universidades públicas, comunitárias e privadas; 2) contemplar a proporção dos programas de mestrado e doutorado consolidados e mais antigos em relação ao universo de programas existentes; 3 ) reproduzir a diversidade de localização geográfica entre as várias regiões do país. Programas da amostra: Região Sul - PUCPR, UEL, UEM, UFPR, UFSC, UNIJUÍ; região Sudeste - PUC/ SP, UFES, UFSCar, UFF, UFMG, UFU, UMESP, USP; região Centro-Oeste - UCDB, UCG, UFG, UFMT, UnB; região Nordeste - UFPB/JP, UFPE, UFPI, UFRN; Região Norte nenhuma.

4 Para ler e elaborar os resumos expandidos, contamos com a colaboração de pesquisadores pertencentes aos Programas selecionados.

Rev. Diálogo Educ., Curitiba, v. 8, n. 23, p. 153-171, jan./abr. 2008 
TABELA 1 - Dissertações e Teses produzidas nos Programas Brasileiros de Pós-Graduação em Educação - período 1990-2002

\begin{tabular}{|c|c|c|c|c|}
\hline Período & Programas & Produção Discente & \multicolumn{2}{|c|}{ Formação de Profissionais } \\
\hline $\begin{array}{c}1990-1996 \\
(7 \text { anos) } \\
1997-2002\end{array}$ & $16 / 24$ & 4.493 & 284 & $6 \%$ \\
\hline (6 anos) & 52 & 8.085 & 1769 & $22 \%$ \\
\hline
\end{tabular}

Amostra investigada neste estudo

\begin{tabular}{|l|l|l|l}
\hline $1997-2002$ & 23 & 742 \\
\hline
\end{tabular}

Em 1997-2002, a temática da Formação de Professores foi objeto de 1.769 trabalhos, representando $22 \%$ do conjunto da produção discente, em comparação com os 284 títulos defendidos no período 1990-1997 e que representaram apenas 6\% da produção na época. O crescimento recente e significativo da pesquisa sobre Formação Docente é reflexo do momento histórico marcado por reformas educacionais na educação básica e por mudanças epistemológicas na pesquisa educacional.

Esse mapeamento serviu de ponto de partida para a seleção de uma amostra representativa formada por 23 Programas, cuja produção somou 742 títulos, a respeito dos quais foram elaborados resumos ampliados, a partir da leitura integral deles.

O material contido nos 742 resumos expandidos foi organizado e sistematizado de acordo com sete grandes categorias: Concep̧ôes de Docência e de Formação de Professores - 47 pesquisas; Políticas de Formação - 64; Formação Inicial 165; Formação Continuada - 115; Trabalho Docente - 268; Identidade e Profissionalizaçãa - 70; e Revisão da Literatura - 13.

Este estudo retoma a produção referente a 4 dessas categorias, num total de 595 trabalhos - Concepsões de Docência e de Formação de Professores, Formação Inicial, Formacão Continuada e Trabalho Docente - selecionando aqueles que abordaram a perspectiva do professor reflexivo/investigativo.

\section{A perspectiva do professor reflexivo/investigativo nas dissertações e teses - período 1997-2000}

Quão expressiva foi a produção sobre o professor reflexivo/ investigativo na amostra que examinamos?

Rev. Diálogo Educ., Curitiba, v. 8, n. 23, p. 153-171, jan./abr. 2008 
A reflexão e investigação da própria prática na formação inicial e continuada

Do universo de 742 dissertações e teses produzidas em 23 programas de Pós-graduação em Educação, no período 1997-2002, 169 abordaram a temática da formação do professor reflexivo/investigativo, representando $22,8 \%$ do total.

Dos 47 estudos que aprofundaram teoricamente as Concepções de Docência e de Formação de Professores, 14 o fizeram segundo os pressupostos do paradigma da racionalidade prática.

Dos 165 trabalhos sobre Formação Inicial, apenas 20 trouxeram experiências em que formadores pesquisaram suas práticas docentes e introduziram os licenciandos em processos de reflexão e investigação.

Dos 383 títulos sobre Formação Continuada e Trabalho Docente, 135 analisaram experiências conduzidas segundo a perspectiva da epistemologia da prática. Reunimos a produção dessas duas categorias porque no período 1997-2002 as pesquisas sobre Formação Continuada detiveram-se na análise de programas governamentais, baseados em grande parte no modelo de racionalidade técnica e desenvolvidos pelas Secretarias de Educação, muitos deles em parceria com Instituições Formadoras, enquanto as pesquisas de formação do professor reflexivo, realizadas pelos professores da educação básica em suas salas de aula, com ou sem a parceria com pesquisadores, foram relatadas na categoria Trabalho Docente.

\section{Estudos teóricos: a natureza da docência e a formação do professor reflexivo/investigativo}

Conforme mostra a Tabela 2, 14 dissertações e teses desenvolveram estudos teóricos sobre a formação do professor reflexivo. Algumas aprofundaram conceitos, fundando-os, sobretudo, em Dewey, Schon, Novoa, Zeichner e Habermas. Outras exploraram ora o caráter dialógico, coletivo, ideológico, histórico da reflexão sobre a prática docente; ora a natureza emancipatória da perspectiva do professor crítico-reflexivo, comprometida com a construção de uma escola e de uma democrática; ora a potencialidade desse movimento como espaço de resistência dos professores às condições institucionais, sociais e econômicas adversas; ora a dimensão criadora e subjetiva da construção dos saberes e da prática docente. Um dos trabalhos explorou as possibilidades de estimular a formação do professor reflexivo/ investigativo mediante projetos de iniciação científica, articulando pesquisa, ensino e extensão. Outro questionou a aproximação entre a perspectiva do professor reflexivo e a formação por competências, perspectiva pragmática que restringe a formação a habilidades operacionais.

Rev. Diálogo Educ., Curitiba, v. 8, n. 23, p. 153-171, jan./abr. 2008 
TABELA 2 - Estudos teóricos sobre a formação do professor reflexivo-investigativo

\begin{tabular}{lllllll}
\hline Foco do Estudo & 97 & 98 & 99 & 00 & 01 & 02 \\
\hline Reflexão + projetos cooperativos & 1 & 1 & & & & 2 \\
Idem + uso da internet & & 1 & & & & \\
Dimensão ético-política/emancipatória & & 1 & 2 & 1 & \\
Dimensão estética, criadora (autoria) & & 1 & 2 & & \\
Form. Reflexiva X form. por competências & & & & 1 & \\
A iniciação científica na form. Inicial & & & & 1 & \\
\hline
\end{tabular}

Esses estudos ressaltaram a importância de espaços de reflexão conjunta na escola. O exame das rotinas e crenças, o confronto e a articulação de perspectiva sobre as práticas pedagógicas e escolares, a partilha de experiências entre os pares contribuiriam para ampliar a compreensão sobre o ensino e sobre o aluno e para superar os vieses inerentes à subjetividade. A atividade sistemática do corpo docente de pensar a escola tiraria o professor do isolamento, criaria condição para a construção do projeto político-pedagógico da escola de forma autônoma e participativa e favoreceria a articulação de projetos de ensino conjuntos, interdisciplinares. Daí a importância da escola enquanto ambiente que propicia a formação contínua dos professores, contribuindo para seu desenvolvimento profissional, e enquanto espaço solidário e democrático, comprometido com a transformação das relações sociais na escola.

Esses estudos exploraram a dimensão reflexiva da atuação docente, mas silenciaram sobre a dimensão investigativa, tal como a concebem Stenhouse e Elliott, segundo os quais as práticas escolares são consideradas como práticas curriculares, a serem constantemente repensadas pela comunidade escolar, transformadas em projetos de ensino a serem experienciados e aperfeiçoados graças à pesquisa que os docentes empreendem sobre sua ação (currículo em movimento), para a qual podem contar com a colaboração de pesquisadores. Nessa perspectiva, a escola torna-se espaço de pesquisa-ação curricular e os professores produtores de conhecimento sobre currículo.

\section{Reflexão e investigação da prática na formação inicial}

Como essas novas idéias repercutiram nos espaços de formação inicial de professores? Estariam os formadores de professores investigando suas práticas docentes? Como introduziram os licenciandos na aprendizagem de refletir e investigar a prática docente? Quais caminhos foram vivenciados nessas experiências formativas?

Rev. Diálogo Educ., Curitiba, v. 8, n. 23, p. 153-171, jan./abr. 2008 
A reflexão e investigação da própria prática na formação inicial e continuada

TABELA 3 - Reflexão e investigação da prática na formação Inicial

\begin{tabular}{|c|c|c|c|c|c|}
\hline 97 & 98 & 99 & 00 & 01 & 02 \\
\hline Normal / Cefam & & & & & 2 \\
\hline \multicolumn{6}{|l|}{ Pedagogia } \\
\hline Disciplinas do conteúdo especif. & & & & 1 & 1 \\
\hline Disciplinas de superv. do estágio & & 1 & & & 2 \\
\hline Projeto Pedagógico & & 1 & & & \\
\hline \multicolumn{6}{|l|}{ Licenciatura } \\
\hline Disciplinas do conteúdo específ. & & & & & 1 \\
\hline Disciplinas pedagógicas & & & 1 & & 1 \\
\hline \multicolumn{6}{|l|}{ Bacharelado } \\
\hline Disciplinas do conteúdo específ. & & 2 & 4 & 2 & \\
\hline Disciplinas de supervisão de estágio & & & & & 1 \\
\hline
\end{tabular}

A Tabela 3 mostra que no período 1997-2002 e na amostra considerada, do total de 165 dissertações e teses que focalizaram a temática da Formação Inicial, apenas em 20 delas os formadores transformaram seu ensino em objeto de pesquisaação, ao mesmo tempo em que oportunizaram aos licenciandos atividades de reflexão e de investigação sobre a própria prática profissional: 9 tiveram lugar no Bacharelado, 6 na Pedagogia, 3 nos cursos de Licenciatura e 2 no Normal / Cefam. A sensibilização dos formadores com a qualidade do ensino e da formação profissional nos cursos de Bacharelado foram um dado inesperado. A baixa freqüência de práticas docentes reflexivas, de projetos de pesquisa-ação ou de pesquisa-ação colaborativa nas disciplinas que visam à formação de professores foi preocupante. Poderia ter sido um viés de nossa amostra, mas esse dado também foi registrado por Romanowski (2000). Na revisão da literatura sobre a Licenciatura no Brasil, a autora igualmente pontua a distância dos cursos de Licenciatura em relação à escola básica e a existência de poucas experiências inovadoras de ensino, isoladas, em geral baseadas em abordagens cognitivistas ou na perspectiva da racionalidade prática de Habermas. Esses dados são indicadores de forte resistência à mudança e de falta de compromisso político e institucional com as questões de ensino e com o preparo profissional dos professores da escola básica, apesar da longa história, em nosso meio, de estudos críticos sobre os cursos de Licenciatura.

Das 20 pesquisas, 9 foram desenvolvidas nas disciplinas pedagógicas em que os alunos deveriam desenvolver atividades de estágio (2 estudos no Normal/Cefam, 4 na Pedagogia, 2 na Licenciatura e 1 no Bacharelado). Entre as atividades reflexivas desenvolvidas, destacaram-se: a) trocas entre professores e

Rev. Diálogo Educ., Curitiba, v. 8, n. 23, p. 153-171, jan./abr. 2008 
licenciandos mediadas pelo pesquisador, responsável pela disciplina; b) projetos de intervenção dos alunos nas classes da escola básica, caracterizados como pequenos projetos de pesquisa-ação, documentados, por vezes videogravados, discutidos e compartilhados nas salas de aulas da faculdade; c) projetos investigativos sobre a história de vida profissional de professores e dos próprios licenciandos; d) estudo e discussão de "casos de ensino", como estratégia para ressignificar a teoria e a prática. Dessas experiências, apenas uma teve caráter interdisciplinar, reunindo formadores, professores e licenciandos de Biologia e de Física em projetos conjuntos de estágio na escola básica.

Houve 10 projetos de pesquisa-ação ou de pesquisa-ação colaborativa, desenvolvidos em diferentes disciplinas do currículo específico: 2 deles tiveram lugar na Pedagogia, 1 na Licenciatura e 6 no Bacharelado (Comunicação, Arquitetura, Engenharia, Ciências Contábeis, Fisioterapia e Zootecnia). Nessas experiências, os alunos tiveram intensa participação: quer refletindo sobre o próprio avanço ou dificuldade no processo de aprendizagem, num curso em que, tradicionalmente, o índice de reprovação era alto; quer registrando em diário experiências de ensino de matemática com uso de computador; quer compartilhando e discutindo os sentidos das próprias produções. Essas experiências foram, entretanto, pontuais, realizadas nos limites temporais e epistemológicos da disciplina, refletindo o isolamento do professor do ensino superior.

Finalmente, uma pesquisa relatou o processo do corpo docente de um curso de Pedagogia de repensar o projeto pedagógico do curso de modo a articular disciplinas das áreas de fundamento com disciplinas aplicadas, num movimento de aproximação entre a formação inicial e a vida profissional.

\section{Reflexão e investigação da prática docente na formação continuada}

Ainda que o exercício da atividade docente seja por si só fator de autoformação do professor, na medida em que a experiência prática coloca desafios e dificuldades, exigindo que ele crie respostas para superá-los, o desenvolvimento profissional dos professores se beneficia da colaboração com pesquisadores e formadores externos, como veremos a seguir.

A Tabela 4 apresenta experiências de Formação Continuada do professor reflexivo / investigativo, no período 1997-2002 e na amostra considerada.

Esses estudos estão agrupados segundo 4 tipos de configuração em que se deu a formação continuada analisada: 1) parceria da universidade com professores; 2) parceria da universidade com escolas; 3) parceria com outros centros formadores; 4) experiências de autoformação.

O primeiro grupo - "parceria da universidade com professores" inclui dois tipos de produção: uma desenvolvida pelo próprio autor da dissertação

Rev. Diálogo Educ., Curitiba, v. 8, n. 23, p. 153-171, jan./abr. 2008 
A reflexão e investigação da própria prática na formação inicial e continuada

ou tese que, sendo professor da escola básica, desenvolveu projeto de pesquisaação em sua disciplina. Ele contou com a orientação de um pesquisador, enquanto aluno do curso de pós-graduação e a pesquisa que empreendeu sobre sua prática seguiu os cânones da academia. Denominamo-la: pesquisa-ação do professorpesquisador. A outra tem como autor um pesquisador que atua como colaborador de um professor ou de um grupo de professores da escola básica que lecionam uma mesma disciplina. Em alguns casos, essa parceria teve o suporte de um núcleo de estudo e pesquisa, sediado na universidade e voltado para a elaboração e implementação de atividades de ensino inovadoras. Denominamos esse subgrupo de pesquisa colaborativa pesquisador-professor(es).

O segundo grupo caracterizado pela parceria universidade-escola é constituído por trabalhos de formação continuada centrados na escola. Aqui, o autor da dissertação ou tese é um pesquisador que na qualidade de colaborador participa do processo de articulação dos professores para pensar a escola, questionar suas práticas, investigá-las e transformá-las.

O terceiro grupo é constituído por estudos que investigaram o trabalho desenvolvido por centros formadores não vinculados a instituições de nível superior.

Finalmente, o quarto grupo descreve experiências de autoformação desenvolvidas por escolas ou por professores da educação básica.

Segundo a Tabela 4, dos 135 títulos que analisaram as atividades de formação continuada segundo um ou outro dos 4 tipos de configuração acima:

- 72 se referem a parcerias entre pesquisadores e professores: em 35 delas o professor-pesquisador descreve a pesquisa-ação por ele desenvolvida na escola básica e em 37 o autor, na qualidade de pesquisador colaborador, analisa o processo e as atividades de formação continuada desenvolvidos pelo professor parceiro ou pelo grupo de professores participantes;

- 28 relatam experiências de pesquisadores centradas na escola;

- 11 abordam o trabalho formativo desenvolvido por outros centros formadores; e

- 24 descrevem experiências de autoformação desenvolvidas pela escola como um todo (14) ou empreendidas pelo compromisso de um ou outro professor da escola básica (10).

Os números acima indicam a importância da figura do colaborador externo na formação do professor reflexivo. Nas condições de trabalho em que atuam nossos professores da escola pública, apenas 24 dos 135 estudos relatam experiências de autoformação.

Que características marcaram as diferentes configurações de formação continuada? Como se deu o processo de aprender a pesquisar a própria prática, atividade nova para o professor? Que pesquisas realizaram os professores? Que mudanças produziram nas práticas escolares? Qual o papel do pesquisador e da universidade nesse processo?

Rev. Diálogo Educ., Curitiba, v. 8, n. 23, p. 153-171, jan./abr. 2008 
TABELA 4 - Reflexão e investigação da prática docente na formação continuada

\begin{tabular}{|c|c|c|c|c|c|c|}
\hline Formação Continuada & 97 & 98 & 99 & 00 & 01 & 02 \\
\hline \multicolumn{7}{|l|}{ Parceria universidade-professor } \\
\hline \multicolumn{7}{|l|}{ Pesquisa-ação do professor-pesquisador } \\
\hline Educação Infantil & 1 & & & & 1 & \\
\hline Ciências & & 1 & 1 & & 4 & 5 \\
\hline Matemática & 1 & & 2 & 2 & 3 & 4 \\
\hline Leitura e produção de texto & & 1 & & 1 & 1 & \\
\hline História & & & & 1 & & 1 \\
\hline Geografia & & & & 1 & 1 & 1 \\
\hline Educação Física & 1 & & & & & \\
\hline Informática & & & & & & 1 \\
\hline \multicolumn{7}{|c|}{ Pesquisa colaborativa pesquisador-professor(es) } \\
\hline Educação Infantil & & 3 & 1 & & & 1 \\
\hline Ciências & 1 & 1 & 2 & 1 & & 1 \\
\hline Matemática & & & & & & 3 \\
\hline Alfabetização / Leitura & & 2 & & & 1 & 2 \\
\hline História & & 1 & & & & \\
\hline Geografia & & 1 & & & & \\
\hline Educação Física & & & & & 1 & 1 \\
\hline Inglês & & 1 & & & & 1 \\
\hline Educação de Jovens e Adultos & & & & & 2 & \\
\hline Educação Inclusiva & & & & 1 & 2 & 3 \\
\hline Informática/Internet & & & & & & 4 \\
\hline \multicolumn{7}{|l|}{ Parceria universidade-escola } \\
\hline Educação infantil & 1 & & & & 1 & 1 \\
\hline EF I & 2 & 1 & 3 & & 2 & 4 \\
\hline EF II & 1 & & 3 & 1 & 3 & 2 \\
\hline Ensino Médio & 1 & & & 1 & & 1 \\
\hline $\begin{array}{l}\text { Parceria com outras instituições formadoras } \\
\text { Experiências de autoformacão }\end{array}$ & & 2 & & 2 & 2 & 5 \\
\hline $\begin{array}{l}\text { Experiências de autoformação } \\
\text { Centradas em escolas }\end{array}$ & 1 & 1 & 1 & 3 & 1 & 7 \\
\hline A prática de "bons professores" & 2 & 1 & 1 & 3 & 1 & 2 \\
\hline TOTAL & 12 & 9 & 12 & 17 & 20 & 33 \\
\hline
\end{tabular}

No primeiro grupo, professores-pesquisadores desenvolveram projetos de pesquisa-ação em suas salas de aula. Exploraram na Educação Infantil o potencial da arte e do lúdico. Nas séries iniciais do Ensino Fundamental, criaram espaços de expressão musical, de leitura como fruição, implementaram projetos construtivistas em alfabetização, estimularam práticas interativas e interpretativas. Nas classes de matemática, as crianças aprenderam a pensar, analisando problemas, tornando seus erros fonte de aprendizagem. Projetos baseados na etnomatemática aproximaram o

Rev. Diálogo Educ., Curitiba, v. 8, n. 23, p. 153-171, jan./abr. 2008 
A reflexão e investigação da própria prática na formação inicial e continuada

estudo da matemática da experiência e da cultura do aluno. Álbuns de família serviram de introdução à aprendizagem da História. No Ensino Fundamental II, foram relatadas experiências de aprendizagem da matemática por solução de problemas. Nas aulas de ciências os projetos, partiram do cotidiano dos alunos, as atividades propiciaram observação, mensuração e análise dos dados, tornando o processo de construção do conhecimento significativo e compreensível para o aluno. No Ensino Médio, houve experiências que estimularam a leitura crítica, o ensino da História a partir da cultura contemporânea, vivida pelo aluno e o uso do laboratório de ciências como espaço de experimentação e de descoberta, e não de mera demonstração. Tais experiências atestam o papel dos Programas de Pós-graduação em Educação na formação de professores reflexivos e investigativos, ainda que, surpreendentemente, tais práticas não tenham aparecido com o mesmo vigor na formação inicial. Entretanto, embora teoricamente bem fundamentadas e bem conduzidas, tiveram caráter pontual, na medida em que não foram apropriadas pela comunidade, apesar de introduzidas por um professor da escola.

Ainda no primeiro grupo, pesquisadores colaboraram com professores parceiros na reflexão e revisão de suas práticas. Aqui também o processo formador se deu no âmbito de cada disciplina curricular. Com exceção das experiências na área de Ciências e Matemática, desenvolvidas por núcleos de pesquisa, a maioria destes estudos envolveu apenas a dupla pesquisador-professor, ou pesquisador- $2 / 3$ professores. A duração da parceria variou de 2 meses a 1 ano e 1/2. Em geral, o enfoque temático não partiu das necessidades dos professores. Foi proposto pelo pesquisador: atividades de ensino sociocnstrutivistas em ciências, experiências reflexivas e interpretativas sobre leitura, uso crítico da propaganda em Geografia, método da solução de problemas, projetos de inclusão. Devido à origem disciplinar que presidiu a formação das parcerias, poucas foram as experiências interdisciplinares. Elas foram propostas numa experiência conduzida pelo laboratório de Informática de uma escola e em projetos de Educação Ambiental. Os caminhos da formação variaram. Alguns foram mais pragmáticos e estruturados, assemelhando-se a oficinas pedagógicas: partiam logo para a elaboração de uma atividade de ensino, consensualmente aceita, vivenciavam-na, partilhavam as dificuldades e acertos durante a implementação. Vários empreenderam projetos investigativos sobre o alunado: análise das fontes de erros nas explicações e nas produções dos alunos; diferentes estruturas de pequenos grupos e suas conseqüências na aprendizagem. Outros se caracterizaram mais como espaços de reflexão e estudo. Um grupo de pesquisa constituiu-se numa comunidade virtual de aprendizagem. Diferentes tipos de registro documentaram os processos formativos e as experiências desenvolvidas pelos professores em sala de aula: diários de campo, atas das reuniões, vídeo das experiências em sala de aula, depoimentos, produções dos alunos, questionários... Os autores referem

Rev. Diálogo Educ., Curitiba, v. 8, n. 23, p. 153-171, jan./abr. 2008 
dificuldades de diferentes ordens, além de manifestações de resistência. O processo não é linear e as mudanças são lentas. Mas os resultados são gratificantes para os professores e para os pesquisadores envolvidos. Entretanto, os relatos são pouco esclarecedores sobre as etapas no processo formativo, sobre as dificuldades encontradas nesse processo, sobre os registros e as atividades investigativas desenvolvidas pelos professores e sua funcionalidade na revisão dos projetos curriculares, sobre o impacto desse tipo de formação nas práticas escolares e no alunado, sobre o aprofundamento dos estudos teóricos, sobre as formas de intervenção feitas pelo pesquisador e sobre as mudanças ocorridas no formador.

Apenas 6 estudos se propuseram avaliar o impacto de parcerias de formação continuada nas representações e práticas dos professores. E eles se restringiram a alguns programas desenvolvidos por núcleos de pesquisa e ensino na área de Ciências.

O segundo grupo, caracterizado pelas pesquisas que relatam experiências de parceria entre a universidade e a escola, constitui um projeto formador mais complexo porque envolve toda a comunidade escolar e requer mais tempo. Esta configuração formativa centrada na escola favorece a participação dos professores, porque todos vivem os mesmos problemas e podem por isso se beneficiar da contribuição dos pares. Favorece as atividades investigativas no interior da escola, engajando os professores no aprofundamento do conhecimento sobre o aluno e sobre diferentes aspectos das práticas escolares: análise de erros dos alunos, problematização do sistema de avaliação da escola e de práticas excludentes. Nessas pesquisas, os professores construíram projetos de ensino coletivos, interdisciplinares, transformaram as relações sociais na escola e refletiram sobre sua história de vida profissional, seu processo formador e sobre a mudança da compreensão de si mesmos, de suas práticas e do significado das práticas escolares, superando sentimentos iniciais de desconforto, culpa e impotência.

O terceiro grupo aborda o trabalho desenvolvido por centros de formação de professores, sem vinculação com centros de formação superior, cuja proposta formativa: a) investe na atitude de "escuta" do aluno, na proposição e avaliação de atividades de ensino teoricamente fundadas, no registro e na partilha (Centro Pedagógico de S. Paulo); b) favorece a autoria do professor, na medida em que promove a socialização de suas experiências nos grupos de estudos ou em congressos (Centro Estadual de Professores do Rio de Janeiro, Grupo de Estudo dos Professores de História da Baixada Santista, Filosofia para Crianças); c) aprofunda a discussão sobre a diversidade cultural e a criação de atividades curriculares baseadas nos valores, nos saberes e nas práticas de comunidades locais (Movimento dos Professores Indígenas, Escolas do Campo); d) está fortemente comprometida com movimentos emancipatórios de educação popular (MST, Instituto Cajamar, em São Paulo).

Rev. Diálogo Educ., Curitiba, v. 8, n. 23, p. 153-171, jan./abr. 2008 
A reflexão e investigação da própria prática

na formação inicial e continuada

Finalmente, o quarto grupo de pesquisas examinou experiências de autoformação de professores em serviço, quer desenvolvidas no coletivo da escola, quer empreendidas por ações isoladas de "bons professores". Quando o processo de formação continuada do professor reflexivo/investigativo nasceu do movimento interno das escolas de pensar, ressignificar e transformar suas práticas, a escola se transformou num espaço formador, capaz de propiciar desenvolvimento profissional docente e num espaço de construção curricular, em que as mudanças adquiriam dinâmica própria, pois representavam uma conquista do grupo. Nesse contexto, os autores das dissertações e teses, na qualidade de observadores participantes, relataram práticas reflexivas e a criação de projetos de ensino baseadas nos valores, saberes e nas práticas dos alunos, projetos curriculares integrados, revisão do projeto pedagógico e das práticas de avaliação, além de várias experiências de gestão participativa. Duas pesquisas retomaram a história do Ensino Vocacional e das Escolas Experimentais de S. Paulo na década de 60 . Por sua vez, práticas de professores qualificados e comprometidos foram observadas. Elas se caracterizavam pela subjetividade. Por meio de entrevistas, procurou-se detectar os sentidos e a intencionalidade subjacentes a tais práticas pedagógicas. A história de vida profissional foi um procedimento importante para desvelar processos de autoformação, desenvolvidos pelos professores, no cotidiano escolar, ao longo de sua vida profissional.

\section{DISCUSSÃO}

Mapear a produção da pesquisa realizada, dando conta do estado do conhecimento na área, oferece aos pesquisadores uma visão compreensiva dos avanços e desafios, situando melhor os recortes relevantes a serem investigados. Mas o volume dessa produção e a dificuldade de localizá-la cria problemas operacionais. Requer a colaboração de muitos e obriga o pesquisador a trabalhar com resumos, incapazes de dar conta da riqueza inerente às experiências de formação do professor reflexivo/investigativo.

As pesquisas examinadas apresentaram referencial teórico densamente tecido e objeto de pesquisa bem definido. Em alguns trabalhos, porém, a descrição da metodologia da pesquisa nem sempre ofereceu dados suficientes sobre os contextos e procedimentos da pesquisa nem explicitou a relação entre os referenciais teóricos e os procedimentos de coleta e de análise interpretativa dos dados. Freqüentemente os fundamentos teóricos, colocados no início da dissertação ou tese, não se articularam com a análise dos dados da pesquisa de campo.

A perspectiva do professor pesquisador de sua prática é recente. Não aparece no Estado do Conhecimento sobre Formação de Professores no

Rev. Diálogo Educ., Curitiba, v. 8, n. 23, p. 153-171, jan./abr. 2008 
Brasil, no período 1990-1996. Nesse período, foram registradas apenas 6 estudos "sobre" a prática docente, em que os professores eram "objetos" e não "sujeitos" da pesquisa.

Esse campo ainda pouco valorizado pela academia oferece muitos contextos a serem explorados, em todos os níveis de ensino, particularmente na Educação Infantil, Ensino Médio, Ensino Técnico-Profissionalizante e na Formação de formadores para o Ensino Superior. Seria importante investigar o potencial transformador desse tipo de pesquisa na cultura universitária, particularmente nos cursos de Licenciatura, embora Zeichner (2003) reconheça que a perspectiva do professor pesquisador ainda não foi incorporada por $2 / 3$ dos programas norte-americanos de formação continuada. A formação para uso interativo e interdisciplinar da Tecnologia de Comunicação e Informação pouco apareceu na nossa casuística.

$\mathrm{Na}$ amostra examinada, o tempo de duração das parcerias foi muito pequeno. Segundo os levantamentos realizados por Borko (2004), as experiências centradas na escola precisariam de mais de 2 anos para apresentarem resultados mais significativos e consolidados.

As experiências de formação do professor reflexivo/investigativo apresentaram enfoques, caminhos e duração diversificados. Ainda assim, pudemos verificar o valor da reflexão conjunta, das trocas, da elaboração de projetos conjuntos e da partilha de experiências como fatores formativos importantes para os professores envolvidos, confirmando os levantamentos norte-americanos apresentados na introdução. Entretanto, outros fatores mencionados nesses estudos, tais como o esclarecimento sobre rotinas, normas e compromisso do grupo e a socialização da pesquisa dos professores em congressos, ou por meio de redes virtuais e de publicações não foram mencionados nos estudos brasileiros.

Finalmente, consideramos importante assinalar o uso, em nossa amostra, da História de Vida como procedimento de pesquisa e como estratégia formativa. Ele não foi mencionado nos levantamentos estrangeiros.

\section{REFERÊNCIAS}

ANDRÉ, M.E.D.A.; ROMANOWSKI, J. O tema da formação de professores nas dissertações e teses (1990-1996). In: ANDRÉ, M. E. D. A. (Org.). Formação dos professores no Brasil (1990-1998). Brasília: MEC/INEP/COMPED, 2002. p. 17-33. (Série Estado do Conhecimento; n. 6). 
BORKO, H. Professional development and teacher learning: mapping the terrain. Educational Researcher, Washington, v. 8 n. 33, p. 3-15, 2004.

COCHRAN-SMITH, M. E LYTLE, S. L. The teacher research movement: a decade later. Educational Researcher, Washington, v. 28, n. 7, p. 15-25, 1999.

GARRIDO, E. Pesquisa universidade-escola e desenvolvimento profissional do professor. 2000. Tese (Livre Docência) - Faculdade de Educação, Universidade de São Paulo, São Paulo, 2000.

NOFFKE, S. Professional, personal and political dimensions of action research. Review of Research in Education, v. 22, n. 1, p. 305-343, 1997.

PUTNAM, L. L. COSTA, Joan; GARRIDO, J. Francisco. Comunicación empresarial -nuevas tendências en la comunicación para ptencializar la estrategia empresarial. Barcelona: Ediciones Gestion, 2002.

ROMANOWSKI, J. P. As licenciaturas no Brasil: um balanço das teses e dissertações dos anos 90. 2000. Tese (Doutorado) - Faculdade de Educação, Universidade de São Paulo, São Paulo, 2002.

ZEICHNER, K. M. Teacher research as professional development for P-12 educators in USA. Educational Action Research Journal, v. 11, n. 2, p. 301-325, 2003.

Recebido: 16/10/2007

Received: $10 / 16 / 2007$

Aprovado: 05/11/2007

Approved: 11/05/2007 